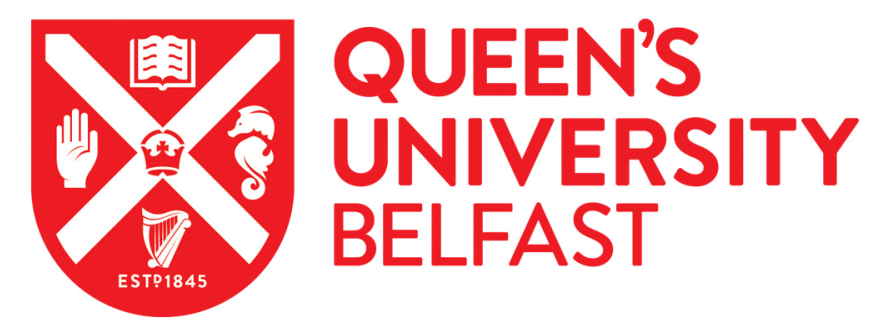

\title{
Mental Health and Morbidity of Caregivers and Co-Residents of individuals with Dementia: A Quasi-Experimental Design
}

Maguire, A., Rosato, M., \& O'Reilly, D. (2016). Mental Health and Morbidity of Caregivers and Co-Residents of individuals with Dementia: A Quasi-Experimental Design. International Journal of Geriatric Psychiatry. https://doi.org/10.1002/gps.4573

Published in:

International Journal of Geriatric Psychiatry

Document Version:

Peer reviewed version

Queen's University Belfast - Research Portal:

Link to publication record in Queen's University Belfast Research Portal

\section{Publisher rights}

Copyright @ 2016 John Wiley \& Sons, Ltd

This is the peer reviewed version of the following article: Maguire, A., Rosato, M., and O'Reilly, D. (2016) Mental health and morbidity of caregivers and co-residents of individuals with dementia: a quasi-experimental design. Int $\mathrm{J}$ Geriatr Psychiatry, which has been published in final form at http://onlinelibrary.wiley.com/wol1/doi/10.1002/gps.4573/abstract. This article may be used for non-commercial purposes in accordance with Wiley Terms and Conditions for Self-Archiving.

\section{General rights}

Copyright for the publications made accessible via the Queen's University Belfast Research Portal is retained by the author(s) and / or other copyright owners and it is a condition of accessing these publications that users recognise and abide by the legal requirements associated with these rights.

\section{Take down policy}

The Research Portal is Queen's institutional repository that provides access to Queen's research output. Every effort has been made to ensure that content in the Research Portal does not infringe any person's rights, or applicable UK laws. If you discover content in the Research Portal that you believe breaches copyright or violates any law, please contact openaccess@qub.ac.uk. 
Mental Health and Morbidity of Caregivers and Co-Residents of individuals with

Dementia: A Quasi-Experimental Design

Authors:

Aideen Maguire $\mathrm{PhD}^{1}$, Michael Rosato $\mathrm{PhD}^{2}$ \& Dermot O'Reilly MD ${ }^{1}$

${ }^{1}$ Centre for Public Health, Queen's University Belfast

${ }^{2}$ Bamford Centre for Mental Health and Wellbeing, Ulster University

\section{Corresponding Author:}

Aideen Maguire

Centre for Public Health

ICSB, Royal Hospitals Site

Grosvenor Road

Belfast

BT12 6BJ

Tel: 0044 (0) 2890971603

E: a.maguire@qub.ac.uk 
2 With an ageing population and an increased desire for older people to remain in their own homes the burden on informal caregivers is increasing (Roth et al., 2015b). Historically, informal caregiving in the USA has been estimated to lead to a saving of approximately \$2billion per year compared to institutional costs (Leon and Moyer, 1999), but there are ongoing concerns about the emotional and physical costs to the caregiver (Capistrant et al., 2014; Schulz and Beach, 1999; Smith et al., 2014). Despite research suggesting that the economic costs for caring for the terminally ill at home are actually greater than that in institutional care (Hollander and Chappell, 2007), the majority of the research points to the cost savings of informal caregiving often overlooking the fact that providing informal care affects an individual's labour market position and well-being (Hassink and Van den Berg, 2011; Leon and Moyer, 1999; Van Den Berg et al., 2014).

Research simultaneously emphasises increased stress and burden associated with informal caregiving whilst demonstrating an associated mortality advantage (Capistrant et al., 2014; O’Reilly et al., 2015a; Ramsay et al., 2013; Roth et al., 2015b; Smith et al., 2014). Earlier reports of the association between caregiving and increased mortality (Schulz and Beach, 1999) have been superseded by more recent studies demonstrating that, compared to noncaregivers, caregiving is associated with a lower mortality risk (Brown et al., 2009; O'Reilly et al., 2015a; Ramsay et al., 2013; Roth et al., 2015b; Smith et al., 2014).

However, the majority of studies have considered caregivers as a homogenous group and few have looked at the variation in mental ill-health or mortality risk of the caregiver according to the health of the care recipient. It is suggested that some caregiving duties, especially those related to dementia care, may be particularly deleterious to health. This is 
important given that the prevalence of dementia is expected to double in next 20 years with an increasing role being played by family caregivers (Ferri et al., 2006). Providing informal care for an individual with dementia is thought to differ from other care scenarios because of the increased demand placed on caregivers due to patient confusion, aggression, personality change and a poor health trajectory (Papastavrou et al., 2012), and the literature generally describes caregiving for individuals with dementia as associated with significantly increased stress, burden and negative mental health consequences (Amirkhanyan and Wolf, 2003; Arai et al., 2014; Ask et al., 2014; Cuijpers, 2005; Loi et al., 2015). However, many of these studies rely on small sample sizes limited to either spousal caregivers (Ask et al., 2014), or parent-child caregivers (Amirkhanyan and Wolf, 2003), others with arguably inappropriate control groups (Roth et al., 2015b). Comparing emotional burden of having a family member with dementia.

Many researchers have cited Pearlin et al's stress pathway to explain why major chronic challenges such as caregiving can have such negative mental health impacts; but have failed to recognise that this pathway may be true for all family members of individuals with dementia (Pearlin et al., 2011), so the oft quoted association between caregiving for someone with dementia and mental well-being may be as much a consequence of witnessing the suffering/deterioration of a family member with a chronic, disabling illness or of anticipatory bereavement, as the effects of caregiving per se (Brown et al., 2009). On the other hand there is growing literature demonstrating that caregiving can be associated with positive attributes including positive self-concept, role approval and a sense of purpose that 
47 may moderate the effect of caregiving stress (Brown and Brown, 2014; Cohen et al., 2002;

48 Hill and Turiano, 2014). There is therefore a need to separate the effects of caregiving from those of other non-caregiving co-residents.

This study capitalises on a unique data linkage to develop a quasi-experimental design, identifying both caregiving and non-caregiving co-residents of individuals with dementia symptoms, to determine if caregivers fare worse than their non-caregiving co-residents. Specifically the study asks - when compared to co-resident non-caregivers, does providing informal care to a household co-resident with dementia symptoms place additional risk on the likelihood of poor mental health or mortality.

\section{METHODS}

\section{Data sources}

The Northern Ireland Mortality Study (NIMS) is a prospective record-linkage study derived from the linkage of census returns to subsequently registered deaths. Details of both the NIMS and the linkage processes are described elsewhere (O'Reilly et al., 2012). For this study all March 2011 Census returns were linked with subsequent associated mortality records from the General Register's Office (GRO), following-up until the end of 2013 (33 months of follow-up). The resulting linked data were anonymised, held in a secure environment by the Northern Ireland Statistics and Research Agency (NISRA) and made available to the research team for the purpose of this study. The use of the NIMS for research was approved by the Office for Research Ethics Committees Northern Ireland (ORECNI). 
Analysis was limited to those living with someone with dementia symptoms. The Census contains information on household structure as well as individuals allowing for the identification of all co-residents of people with dementia symptoms. The 2011 Census contains a health question asking "Do you have any of the following conditions which have lasted, or are expected to last, at least 12 months?" - listing ten conditions including "Frequent periods of confusion or memory loss". Positive responses to this question were used as a proxy for cognitive decline, termed "dementia symptoms" throughout the remainder of this paper. To minimise misclassification we limited identification of dementia symptoms to those individuals aged 65 years and over. Single item screening questions for dementia have been shown to be effective in informants (Ayalon, 2011; Hendry et al., 2015), and often one person fills in the Census for the household. Over 1.8 million individuals $(1,810,863)$ were enumerated in the 2011 Census of which 19,845 were identified as having dementia symptoms. This corresponds favourably with the Alzheimer's Society's estimate for diagnosed/undiagnosed dementia in the Northern Ireland population - estimated at 19,765 in 2013/14 based on the National Health Service Quality and

Outcomes Framework indicator from General Practitioner records (Alzheimer's Society, $2014)$ - thus reinforcing the criterion validity of this dementia proxy.

\section{Co-resident caregivers and non-caregivers}

Co-residents, living with an individual with dementia symptoms, were divided into two categories; caregivers and non-caregivers (Figure 1). The assessment of caregiving responsibilities was derived from the Census question: "Do you look after, or give any help 
physical or mental ill-health/disability?; problems related to old age?" Respondents were instructed not to include anything they did as part of their paid employment. This method has been utilised in previous literature (O’Reilly et al., 2015a; Ramsay et al., 2013).

Caregiving intensity was measured by responses to the number of hours care provided each week: none (non-caregiver); caregiving for 1-19 hours; caregiving for more than 20 or more hours per week. While the Census did not ask any further questions about either the carerecipient or the type of care provided, it was assumed that caregivers living with an individual with dementia symptoms were providing care for their ill co-resident.

Households with more than one caregiver were included and it was assumed all household caregivers were caring for the ill co-resident. Sensitivity analysis was carried out limited to households with only one caregiver. Those living alone or in a communal establishment were removed from analysis leaving 8,604 individuals with dementia symptoms living with 10,982 caregiving and non-caregiving co-residents (Figure 1).

(Figure 1 about here)

\section{Cohort attributes}

Personal characteristics of co-residents were drawn from the Census: including age, gender and marital status (grouped as never married; married; widowed, separated or divorced). As Northern Ireland is an ethnically homogenous country ethnic diversity was summarised as white/non-white. Other cohort attributes known to be associated with poor mental health were identified from the Census including educational attainment (no formal qualifications, 
foundation level, completed compulsory schooling up to age 16 years, completed A-levels at age 18 years, and University degree or higher) and socioeconomic status was assessed using a combination of housing tenure and the capital value of the property. Tenure was derived directly from the Census (owner occupiers, private renting or social renting). Capital value had been derived as part of an exercise by central government in 2005 to determine the level of local tax payable by each household. These data were linked and combined with tenure to produce an eight-fold classification defining tenure/taxable value of property (private renting; social renting; and for owner-occupiers, five groups ranging from less than $£ 75 k$ to over $£ 200 k$ ) (see Table 1 ), with a separate category for owners with unvalued homes. Physical health was determined from the limiting long-term illness question, "Are your day to day activities limited because of a health problem or disability which has lasted, or is expected to last, at least 12 months?" Respondents could identify "Yes, limited a lot", "Yes, limited a little" or "No". This was aggregated to a binary Yes/No outcome, and has been identified in previous work as an accurate indicator of physical health (Cohen et al., 1995).

\section{Area characteristics}

130 Area level deprivation was assigned using the "Income" domain of the Northern Ireland Index of Multiple Deprivation (NIMDM) which includes an assessment of the proportion of individuals in an area on means-tested benefits (NISRA, 2010). Areas were defined as 890 homogenous groups of approximately 1,900 individuals and were ranked from least deprived to most deprived, then split into equal quintiles. An indicator of urban-rural residence was based on the NISRA classification of Settlements (grouped as urban, 
intermediate and rural locales representing settlements of $>75,000$ people, $2500-75000$ and

$137<2500$ people respectively) (NISRA, 2005).

\section{Mental Health status}

Individuals were identified as suffering from poor mental health by the health question in the Census "Do you have any of the following conditions which have lasted, or are expected to last, at least 12 months?" Those who identified as suffering from "An emotional, psychological or mental health condition (such as depression or schizophrenia)" were defined as having poor mental health. This indicator has face validity based on its demographic distribution which mirrors known associations with mental health, and predictive validity as it is a strong predictor of death by suicide and has been used in previous research as an indicator of mental well-being (Tseliou et al., 2015).

\section{Death}

Death information from official death records was linked probabilistically to Census data, identifying those who died in the follow-up period between April 2011 and December 2013. Methods of these linkages processes are described in detail elsewhere (O'Reilly et al., 2008b).

\section{Analysis Strategy}

The design allocated co-residents of individuals with dementia symptoms into caregiving or non-caregiving groups, with the non-caregiving co-residents providing a natural comparator for the additive effects of caregiving on top of the effect of living with an individual with dementia symptoms. Descriptive statistics recorded the socio-demographic characteristics and variations in health status and mortality co-residents. Multi-level regression models compared the risks associated with both poor mental health and mortality of co-resident 
carers with co-resident non-carers, adjusting for the clustering of individuals within households. The distribution of mental health or mortality risk may not only be explained by characteristics of the individuals but also by unmeasured characteristics of the household. Multi-level modelling adjusts for this clustering of individuals within household and allows for the calculation of a Variance Partition Co-efficient (VPC) to determine the amount of variation attributable to the second level co-variate, in this instance, household variation. Interactions between independent variables were tested for moderation effects based on strong suggestions from the descriptive statistics and the literature.

\section{RESULTS}

The study sample consisted of 10,982 co-residents of individuals with dementia symptoms, 4,928 (44.9\%) non-caregivers and 6,054 (55.1\%) caregivers. The mean age of individuals with dementia symptoms was 78.1 years and of co-residents, 59.3 years with the majority of the cohort white (97.6\%). Caregiving and non-caregiving co-residents varied according to their demographic characteristics (Table 1). Caregivers were better educated, lived in more affluent households and had better physical and mental health compared to non-caregivers. There were differences between light and more intense caregivers. Those providing intense care ( $>20$ hours per week) tended to be older with a higher proportion of females compared to light caregivers ( $<20$ hours per week) and non-caregiving co-residents. Non-caregiving co-residents tended to live in less deprived areas yet report poorer physical and mental health compared to caregivers. A higher proportion of light caregivers were male, younger, never married, had higher educational attainment and house value, and better mental and physical health compared to both intense caregivers and non-caregivers (Table 1). 
Overall, $12 \%$ of non-caregiving co-residents reported chronic poor mental health compared to $6 \%$ and $8 \%$ for those providing respectively light and more intensive caregiving duties. Multi-level models determined the likelihood of poor mental health in co-resident caregivers compared to co-resident non-caregivers adjusting for the clustering of individuals within households. Caregiving co-residents, as a group, were at no greater risk of poor mental health compared to non-caring co-residents $(\mathrm{OR}=0.93,95 \% \mathrm{Cl} 0.79,1.10)$ [Results available on request] and Table 2 shows the results of the models separating light and intense caregivers. In the unadjusted model co-resident caregivers providing light care were $55 \%$ less likely to report poor mental health compared to co-resident non-caregivers $(\mathrm{OR}=0.45,95 \% \mathrm{Cl} 0.32,0.61)$, and caregivers providing more intense care $44 \%$ less likely to report poor mental health $(\mathrm{OR}=0.56,95 \% \mathrm{Cl} 0.46,0.67)$. Adjusting for age, gender, marital status, ethnicity, education and socio-economic status (Model 3) attenuated the relationship slightly but the protective association between caregiving and mental health remained. After adjusting for baseline physical health (Model 4) the association disappeared and there was no significant difference in likelihood of poor mental health between co-resident caregivers and non-caregivers. The amount of variation attributable to the clustering was calculated using the variance partition co-efficient (VPC). The VPC in the fully adjusted model (Model 5) suggests approximately $32 \%$ of the variance in propensity to having poor mental health is attributable to household differences, highlighting a substantial influence of household on mental health. 
Given the observed disparity in gender distribution of caregiving roles, possible interactions between gender and care provision were tested using likelihood ratio tests with no significant interaction ( $L R$ test $=5.44 \mathrm{P}=0.07)$.

(Table 2 about here)

Multi-level models were constructed to determine the risk of mortality in co-resident

caregivers compared to co-resident non-caregivers adjusting for the clustering of individuals within households. Overall, caregiving co-residents were 33\% less likely to die during the study period than non-caring co-residents after adjustment for all characteristics described in Table $1(\mathrm{OR}=0.67,95 \% \mathrm{Cl} 0.56,0.81)$ [Results available on request]. Table 3 shows the results of the models separating light and intense caregivers. In the unadjusted model individuals providing light care ( $<20$ hours/week) are $83 \%$ less likely to die compared to those not providing care $(\mathrm{OR}=0.17,95 \% \mathrm{Cl} 0.06,0.44)$. Providing intense care resulted in a $59 \%$ reduced likelihood of death compared to co-resident non-caregivers (OR=0.41, $95 \% \mathrm{Cl}$ $0.26,0.67)$. After full adjustment for factors known to be associated with mortality risk; age, gender, marital status, ethnicity, educational attainment, socio-economic status, physical health, area level deprivation and urbanicity, individuals providing intense care to their coresidents with dementia were $36 \%$ less likely to die than those not providing care $(O R=0.64$, $95 \% \mathrm{Cl} 0.53,0.78)$. Possible interactions between gender and care provision were tested using likelihood ratio tests with no significant interaction between gender and care provision for risk of death (LR test $=2.93 p=0.23$ ). The VPC in this fully adjusted model (Model 5) suggests that over and above the factors for which we have already adjusted, only 


\section{DISCUSSION}

This large, representative study demonstrates that: (i) caregivers to those with dementia symptoms are no more likely than co-resident non-caregivers to report having poor mental health, and (ii) caregiving is associated with a lower mortality risk when compared to noncaregiving co-residents. That caregiving is not associated with any additional risk of poor mental health supports Brown et al.'s recent recommendation for caution before concluding that the negative effects observed in caregiving are due to the provision of care to another person (Brown and Brown, 2014) and suggests a need for researchers to be more careful about their choice of comparator in studies of informal caregiving. Our findings concur with an earlier USA study that showed that having a close family member, such as a spouse/elderly parent, with dementia or other serious disability can lead to stress or depressive symptoms regardless of whether or not the unaffected family member is providing care (Amirkhanyan and Wolf, 2003). Furthermore, even in these difficult circumstances, not everyone may be affected, and Vitaliano et $a$ in a unique twin-study suggests that the relationship between caregiving and psychological distress may be determined by a vulnerability largely shaped by genetic and early life factors (Vitaliano et al., 2014). Results from the multi-level models in our study purport that $33 \%$ of the variation in mental health is due to household factors, which would explain why household

247 stressors such as living with someone with dementia symptoms could have the same influence on both caregiving and non-caregiving household members. 
250 This study clearly suggests that being a caregiver for someone with dementia is associated

251 with a lower mortality risk than experienced by other co-residents and although this is at odds with earlier studies (Schulz and Beach, 1999; Schulz et al., 1995), it is in keeping with more recent studies reporting a significant mortality advantage associated with caregiving (Brown et al., 2009; Fredman et al., 2010; O’Reilly et al., 2015b, 2008a; Ramsay et al., 2013; Roth et al., 2015b, 2013) and with Brown et al. who showed that providing more than 14 hours care per week is associated with decreased mortality risk independent of the care demands of the care recipient (Brown et al., 2009). The reason for the lower mortality risk amongst caregivers is not entirely clear but may be related to feelings of usefulness that may shape health trajectories in older adults (Gruenewald et al., 2007), and non-caring coresidents do not get the rewards associated with caring such as satisfaction, sense of purpose or the patient-carer bond. Prosocial behaviour has been hypothesized to be part of a chain of related biochemical events that function to reduce stress and inflammation and, helper's health and longevity (Brown and Brown, 2015).

\section{Potential Limitations}

The Census data are comprehensive and, by definition, representative of the entire population, with complete coverage of deaths and detailed information on individual-level health and socio-economic status for accurate adjustment in the models. While representativeness and generalisability of findings are always a concern, the socio- 
demographic, socioeconomic and health characteristics of caregivers in this study correspond well with other reports (O'Reilly et al., 2015a; Ramsay et al., 2013; Smith et al., 2014), endorsing the reliability of these results. Northern Ireland's dementia care strategy aims to help individuals remain in their own home as long as possible and like the majority of countries in Europe, home care is the predominant care setting (DHSSPS, 2011; Rodrigues et al., 2012). One major limitation of this study lies in assumptions derived of the data. While the indicator of dementia symptoms is a self-reported measure of "experience of confusion or memory loss" (i.e. not clinically diagnosed dementia), it correlates very well to independent population estimates (Alzheimer's Society, 2014), has reasonable face validity and by limiting potential care recipients to those aged 65 years and over we can be more confident that these symptoms are associated with dementia. We also assumed that caregivers within a household are providing care for their ill co-residents but note that this methodology has been used successfully elsewhere (O'Reilly et al., 2015a; Ramsay et al., 2013).

Another limitation is that we cannot be sure that co-residents who did not identify as caregivers are not undertaking any caring duties, i.e. they may be providing care but do not see their roles as an "informal caregiver" but just undertaking normal family duties. This potential misclassification would not however alter our main conclusion that there is a need to include the entire family in any support given to the family of individuals with dementia, not merely those who identify as the main caregiver. The healthy caregiver effect is a major concern and although there is some evidence that the people who undertake a caregiving role are healthier than those who do not, the relatively small change in odds ratios (Table 3, Model 4) after adjustment for health status at baseline suggests that the associated 
mortality advantage is not primarily due to health selection. Finally, we acknowledge that the cross-sectional nature of some outputs of the study do not allow consideration of the dynamic nature of caring which has fluctuations in demand and burden.

\section{Implications}

The implications of this study are twofold. Firstly, the results add weight to current recommendations for the need to reassess how the risks and benefits associated with caregiving are perceived and reported both in the scientific and in the popular press (Roth et al., 2015a). Secondly, it highlights an often overlooked at-risk group, those non-caregiving co-residents of individuals with dementia symptoms. Whilst previous work focussing on the mental health of dementia "patient-carer" dyads has attributed most of the observed adverse consequences to the provision of care, it may be that having a family member with dementia, and not the caregiving per se, is the pertinent risk factor for poor mental health.

\section{Acknowledgments:}

The help provided by the staff of the Northern Ireland Mortality Study (NIMS) and the Northern Ireland Longitudinal Study (NILS) Research Support Unit is acknowledged. The NIMS is funded by the Health and Social Care Research and Development Division of the Public Health Agency (HSC R\&D Division) and NISRA. The NILS-RSU is funded by the ESRC and the Northern Ireland Government. The authors alone are responsible for the interpretation of the data and any views or opinions presented are solely those of the author and do not necessarily represent those of NISRA/NILS. 
318 Conflict of interest:

319 No Disclosures to Report

320

321 Ethics:

322 This study was approved by the Office for Research Ethics Committees Northern Ireland. 
Table 1: Characteristics of dementia patient co-residents ( $n=10,982)$

\begin{tabular}{|c|c|c|c|c|c|}
\hline & & $\begin{array}{c}\text { Non- carers } \\
(4,928)\end{array}$ & $\begin{array}{l}\text { Light caring } \\
\text { responsibility } \\
(1,155)\end{array}$ & $\begin{array}{c}\text { Heavy } \\
\text { caring responsibility } \\
(4,899)\end{array}$ & $\begin{array}{c}\text { All } \\
(10,982)\end{array}$ \\
\hline Age & Mean (years) & $57.6 y r s$ & $51.7 \mathrm{yrs}$ & $62.7 \mathrm{yrs}$ & 59.3yrs \\
\hline \multirow[t]{2}{*}{ Gender (\%) } & Male & 52.7 & 59.3 & 43.5 & 49.3 \\
\hline & Female & 47.3 & 40.7 & 56.5 & 50.7 \\
\hline Marital Status & Never married & 38.7 & 44.5 & 25.3 & 33.3 \\
\hline \multirow[t]{2}{*}{ 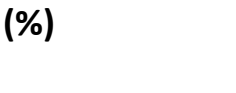 } & Married/Co-habiting & 53.8 & 48.0 & 68.1 & 59.6 \\
\hline & Separated/Divorced/Widowed & 7.6 & 7.5 & 6.5 & 7.1 \\
\hline Household & 2 people & 45.2 & 33.7 & 58.1 & 49.8 \\
\hline \multirow[t]{3}{*}{ Size (\%) } & 3 people & 26.6 & 27.7 & 23.4 & 25.3 \\
\hline & 4 people & 12.0 & 14.5 & 8.5 & 10.7 \\
\hline & $5+$ people & 16.1 & 24.2 & 10.0 & 14.2 \\
\hline \multirow[t]{5}{*}{ Education (\%) } & No qualifications & 55.6 & 25.2 & 46.8 & 48.4 \\
\hline & Foundation & 17.1 & 18.7 & 18.6 & 17.9 \\
\hline & Compulsory Schooling & 9.0 & 13.9 & 9.8 & 9.9 \\
\hline & A levels & 6.7 & 12.7 & 6.4 & 7.2 \\
\hline & Degree+ & 11.7 & 29.4 & 18.4 & 16.6 \\
\hline House Tenure & Social Renting & 17.9 & 9.0 & 14.6 & 15.5 \\
\hline \multirow[t]{7}{*}{ (\%) } & Private Renting & 7.2 & 5.5 & 7.0 & 6.9 \\
\hline & Missing & 5.1 & 8.1 & 4.8 & 5.3 \\
\hline & $<£ 75,000$ & 13.4 & 6.4 & 11.2 & 11.7 \\
\hline & $£ 75,000-£ 99,999$ & 17.2 & 16.2 & 17.4 & 17.2 \\
\hline & £100K - £149,999 & 22.2 & 25.4 & 22.8 & 22.8 \\
\hline & £150k - £199,999 & 10.4 & 14.5 & 12.5 & 11.8 \\
\hline & $£ 200 K+$ & 6.7 & 15.0 & 9.7 & 8.9 \\
\hline IIIness (\%) & LLTI & 56.3 & 29.9 & 45.4 & 48.7 \\
\hline Deprivation & Deprived & 16.0 & 21.4 & 20.5 & 18.6 \\
\hline \multirow[t]{4}{*}{ (\%) } & 2 & 16.7 & 22.1 & 18.8 & 18.2 \\
\hline & 3 & 20.9 & 18.4 & 18.7 & 19.6 \\
\hline & 4 & 21.3 & 18.5 & 20.7 & 20.7 \\
\hline & Affluent & 25.2 & 19.6 & 21.4 & 22.9 \\
\hline \multirow[t]{4}{*}{ Urban (\%) } & Rural & 31.3 & 36.2 & 28.5 & 30.0 \\
\hline & Intermediate & 30.7 & 28.8 & 29.8 & 30.1 \\
\hline & Urban & 36.7 & 31.9 & 40.3 & 38.7 \\
\hline & Missing & 1.3 & 3.1 & 1.4 & 1.5 \\
\hline \multirow[t]{3}{*}{ Health (\%) } & Psychological or Emotional & & & & \\
\hline & problem & 12.1 & 6.4 & 8.4 & 9.8 \\
\hline & Died & 6.4 & 3.9 & 4.2 & 5.1 \\
\hline
\end{tabular}


Table 2: Multi-level logistic regression model illustrating the likelihood of poor mental health in dementia patient's co-residents, given informal care-giving status; adjusting for the clustering of individuals within households. Figures represent Odds Ratios \& 95\% Confidence Intervals

\begin{tabular}{|c|c|c|c|c|c|c|c|}
\hline & Co-resident status & Unadjusted & $\begin{array}{l}\text { Model } 1 \\
\text { Adjusted age \& } \\
\text { gender }\end{array}$ & $\begin{array}{l}\text { Model } 2 \\
\text { +marital status, } \\
\text { ethnicity \& HH size }\end{array}$ & $\begin{array}{l}\text { Model } 3 \\
+ \text { SES (tenure \& } \\
\text { education) }\end{array}$ & $\begin{array}{l}\text { Model } 4 \\
+ \text { baseline } \\
\text { health (LLTI) }\end{array}$ & $\begin{array}{l}\text { Model } 5 \\
+ \text { area deprivation } \\
\text { \& urbanicity }\end{array}$ \\
\hline & Not a carer & 1.00 & 1.00 & 1.00 & 1.00 & 1.00 & 1.00 \\
\hline & Light care (<20hrs) & $0.45(0.32,0.61)$ & $0.41(0.30,0.56)$ & $0.42(0.31,0.57)$ & $0.52(0.38,0.71)$ & $0.78(0.57,1.07)$ & $0.78(0.57,1.08)$ \\
\hline & Heavy care (>20 hrs) & $0.56(0.46,0.67)$ & $0.60(0.50,0.72)$ & $0.59(0.50,0.71)$ & $0.65(0.55,0.76)$ & $0.96(0.81,1.15)$ & $0.97(0.81,1.15)$ \\
\hline \multirow[t]{2}{*}{ Gender } & Male & & 1.00 & 1.00 & 1.00 & 1.00 & 1.00 \\
\hline & Female & & $1.17(0.99,1.38)$ & $1.23(1.05,1.45)$ & $1.27(1.08,1.49)$ & $1.20(1.02,1.41)$ & $1.20(1.02,1.41)$ \\
\hline Age & Age (continuous) & & $0.98(0.97,0.99)$ & $0.98(0.97,0.99)$ & $0.98(0.97,0.99)$ & $0.96(0.95,0.96)$ & $0.96(0.95,0.96)$ \\
\hline Marital & Never married & & & 1.00 & 1.00 & 1.00 & 1.00 \\
\hline \multirow[t]{2}{*}{ Status } & Married/Co-habit & & & $1.30(1.02,1.66)$ & $1.26(0.99,1.60)$ & $1.38(1.07,1.76)$ & $1.37(1.07,1.76)$ \\
\hline & Sep/Div/Wid & & & $2.09(1.55,2.82)$ & $1.82(1.35,2.45)$ & $2.00(1.47,2.74)$ & $1.97(1.44,2.69)$ \\
\hline \multirow[t]{2}{*}{ Ethnicity } & White & & & 1.00 & 1.00 & 1.00 & 1.00 \\
\hline & Non-while & & & $0.38(0.16,0.87)$ & $0.43(0.19,1.00)$ & $0.68(0.29,1.56)$ & $0.68(0.29,1.58)$ \\
\hline Household & 2 people & & & 1.00 & 1.00 & 1.00 & 1.00 \\
\hline \multirow[t]{3}{*}{ Size } & 3 people & & & $0.84(0.68,1.03)$ & $0.96(0.78,1.18)$ & $1.00(0.81,1.23)$ & $1.00(0.81,1.23)$ \\
\hline & 4 people & & & $0.54(0.39,0.75)$ & $0.66(0.48,0.91)$ & $0.75(0.54,1.03)$ & $0.75(0.54,1.04)$ \\
\hline & $5+$ people & & & $0.40(0.29,0.56)$ & $0.54(0.39,0.75)$ & $0.74(0.54,1.03)$ & $0.74(0.54,1.04)$ \\
\hline \multirow[t]{8}{*}{ Tenure } & Social Renting & & & & 1.00 & 1.00 & 1.00 \\
\hline & Private Renting & & & & $0.54(0.39,0.77)$ & $0.60(0.42,0.85)$ & $0.64(0.45,0.92)$ \\
\hline & Missing & & & & $0.23(0.14,0.38)$ & $0.31(0.18,0.51)$ & $0.32(0.19,0.56)$ \\
\hline & $<£ 75,000$ & & & & $0.34(0.25,0.47)$ & $0.43(0.32,0.59)$ & $0.45(0.33,0.61)$ \\
\hline & $£ 75,000-£ 99,999$ & & & & $0.47(0.36,0.61)$ & $0.56(0.43,0.73)$ & $0.59(0.45,0.77)$ \\
\hline & £100K - £149,999 & & & & $0.39(0.30,0.50)$ & $0.47(0.36,0.61)$ & $0.52(0.39,0.68)$ \\
\hline & $£ 150 k-£ 199,999$ & & & & $0.31(0.22,0.44)$ & $0.39(0.28,0.58)$ & $0.45(0.31,0.64)$ \\
\hline & $£ 200 K+$ & & & & $0.27(0.18,0.40)$ & $0.37(0.25,0.56)$ & $0.43(0.28,0.67)$ \\
\hline \multirow[t]{4}{*}{ Education } & No qualifications & & & & 1.00 & 1.00 & 1.00 \\
\hline & Foundation & & & & $1.42(1.09,1.85)$ & $0.85(0.64,1.12)$ & $0.84(0.63,1.10)$ \\
\hline & Compulsory School & & & & $1.30(0.97,1.75)$ & $1.07(0.79,1.45)$ & $1.05(0.78,1.43)$ \\
\hline & A levels & & & & $1.23(0.89,1.72)$ & $1.04(0.74,1.47)$ & $1.03(0.73,1.45)$ \\
\hline
\end{tabular}




\begin{tabular}{|c|c|c|c|c|c|c|c|}
\hline \multirow{3}{*}{ Illness } & Degree+ & & & & $0.97(0.66,1.41)$ & $0.91(0.62,1.35)$ & $0.91(0.61,1.34)$ \\
\hline & No & & & & & 1.00 & 1.00 \\
\hline & Yes & & & & & $\begin{array}{l}17.53 \\
(13.29,23.12)\end{array}$ & $17.51(13.28,23.10)$ \\
\hline \multirow[t]{5}{*}{ Deprivation } & Deprived & & & & & & 1.00 \\
\hline & 2 & & & & & & $0.83(0.60,1.13)$ \\
\hline & 3 & & & & & & $1.06(0.78,1.44)$ \\
\hline & 4 & & & & & & $1.12(0.83,0.51)$ \\
\hline & Affluent & & & & & & $1.23(0.91,1.65)$ \\
\hline \multirow[t]{6}{*}{ Urban } & Rural & & & & & & 1.00 \\
\hline & Intermediate & & & & & & $1.08(0.86,1.37)$ \\
\hline & Urban & & & & & & $1.03(0.81,1.30)$ \\
\hline & Missing & & & & & & $1.38(0.62,3.08)$ \\
\hline & Variance & 3.20 & 3.13 & 2.39 & 2.12 & 1.58 & 1.57 \\
\hline & VPC & 0.49 & 0.49 & 0.42 & 0.39 & 0.32 & 0.32 \\
\hline
\end{tabular}


Table 3: Multi-level logistic regression model illustrating the likelihood of mortality in dementia patient's co-residents, given informal care-giving status; adjusting for the clustering of individuals within households. Figures represent Odds Ratios \& 95\% Confidence Intervals

\begin{tabular}{|c|c|c|c|c|c|c|c|}
\hline & Co-resident status & Unadjusted & $\begin{array}{l}\text { Model } 1 \\
\text { Adjusted age \& } \\
\text { gender }\end{array}$ & $\begin{array}{l}\text { Model } 2 \\
\text { +marital status, } \\
\text { ethnicity \& HH size }\end{array}$ & $\begin{array}{l}\text { Model } 3 \\
+ \text { SES (tenure \& } \\
\text { education) }\end{array}$ & $\begin{array}{l}\text { Model } 4 \\
+ \text { baseline health } \\
\text { (LTTI) }\end{array}$ & $\begin{array}{l}\text { Model } 5 \\
+ \text { area deprivation } \\
\& \text { urbanicity }\end{array}$ \\
\hline & Not a carer & 1.00 & 1.00 & 1.00 & 1.00 & 1.00 & 1.00 \\
\hline & Light care (<20hrs) & $0.17(0.06,0.44)$ & $0.71(0.49,1.02)$ & $0.70(0.49,1.00)$ & $0.77(0.54,1.12)$ & $0.82(0.57,1.19)$ & $0.84(0.58,1.21)$ \\
\hline & Heavy care (>20 hrs) & $0.41(0.26,0.67)$ & $0.59(0.48,0.71)$ & $0.59(0.48,0.71)$ & $0.60(0.50,0.73)$ & $0.65(0.54,0.80)$ & $0.65(0.53,0.79)$ \\
\hline \multirow[t]{2}{*}{ Gender } & Male & & 1.00 & 1.00 & 1.00 & 1.00 & 1.00 \\
\hline & Female & & $0.49(0.41,0.59)$ & $0.49(0.41,0.59)$ & $0.50(0.41,0.60)$ & $0.49(0.41,0.59)$ & $0.48(0.40,0.59)$ \\
\hline Age & Age (continuous) & & $1.10(1.09,1.11)$ & $1.10(1.09,1.11)$ & $1.10(1.09,1.11)$ & $1.09(1.08,1.10)$ & $1.09(1.08,1.10)$ \\
\hline Marital & Never married & & & 1.00 & 1.00 & 1.00 & 1.00 \\
\hline \multirow[t]{2}{*}{ Status } & Married/Co-habit & & & $1.12(0.82,1.52)$ & $1.13(0.83,1.53)$ & $1.17(0.85,1.59)$ & $1.21(0.89,1.66)$ \\
\hline & Sep/Div/Wid & & & $0.83(0.53,1.29)$ & $0.77(0.49,1.21)$ & $0.84(0.54,1.31)$ & $0.81(0.52,1.27)$ \\
\hline \multirow[t]{2}{*}{ Ethnicity } & White & & & 1.00 & 1.00 & 1.00 & 1.00 \\
\hline & Non-while & & & $0.54(0.07,4.01)$ & $0.58(0.08,4.36)$ & $0.61(0.08,4.65)$ & $0.57(0.08,4.32)$ \\
\hline Household & 2 people & & & 1.00 & 1.00 & 1.00 & 1.00 \\
\hline \multirow[t]{3}{*}{ Size } & 3 people & & & $0.94(0.74,1.20)$ & $0.97(0.76,1.23)$ & $0.97(0.76,1.24)$ & $0.98(0.77,1.25)$ \\
\hline & 4 people & & & $0.81(0.51,1.27)$ & $0.85(0.54,1.35)$ & $0.86(0.55,1.37)$ & $0.91(0.57,1.44)$ \\
\hline & $5+$ people & & & $1.20(0.81,1.79)$ & $1.33(0.88,2.00)$ & $1.42(0.94,2.15)$ & $1.47(0.96,2.23)$ \\
\hline \multirow[t]{8}{*}{ Tenure } & Social Renting & & & & 1.00 & 1.00 & 1.00 \\
\hline & Private Renting & & & & $0.85(0.59,1.23)$ & $0.87(0.61,1.26)$ & $0.94(0.65,1.36)$ \\
\hline & Missing & & & & $0.63(0.38,1.03)$ & $0.68(0.41,1.13)$ & $0.78(0.46,1.35)$ \\
\hline & $<£ 75,000$ & & & & $0.77(0.56,1.08)$ & $0.82(0.59,1.15)$ & $0.87(0.63,1.22)$ \\
\hline & $£ 75,000-£ 99,999$ & & & & $0.77(0.57,1.04)$ & $0.81(0.60,1.10)$ & $0.85(0.63,1.16)$ \\
\hline & £100K - £149,999 & & & & $0.60(0.45,0.81)$ & $0.65(0.48,0.88)$ & $0.70(0.51,0.95)$ \\
\hline & f150k - f199,999 & & & & $0.71(0.50,1.00)$ & $0.79(0.55,1.10)$ & $0.81(0.56,1.18)$ \\
\hline & f200K+ & & & & $0.65(0.43,0.99)$ & $0.73(0.48,1.12)$ & $0.75(0.48,1.18)$ \\
\hline \multirow[t]{4}{*}{ Education } & No qualifications & & & & 1.00 & 1.00 & 1.00 \\
\hline & Foundation & & & & $1.47(1.06,2.03)$ & $1.32(0.95,1.82)$ & $1.38(0.99,1.93)$ \\
\hline & Compulsory School & & & & $1.50(1.03,2.19)$ & $1.41(0.97,2.06)$ & $1.42(0.97,2.08)$ \\
\hline & A levels & & & & $1.23(0.72,2.12)$ & $1.20(0.70,2.08)$ & $1.22(0.71,2.12)$ \\
\hline
\end{tabular}




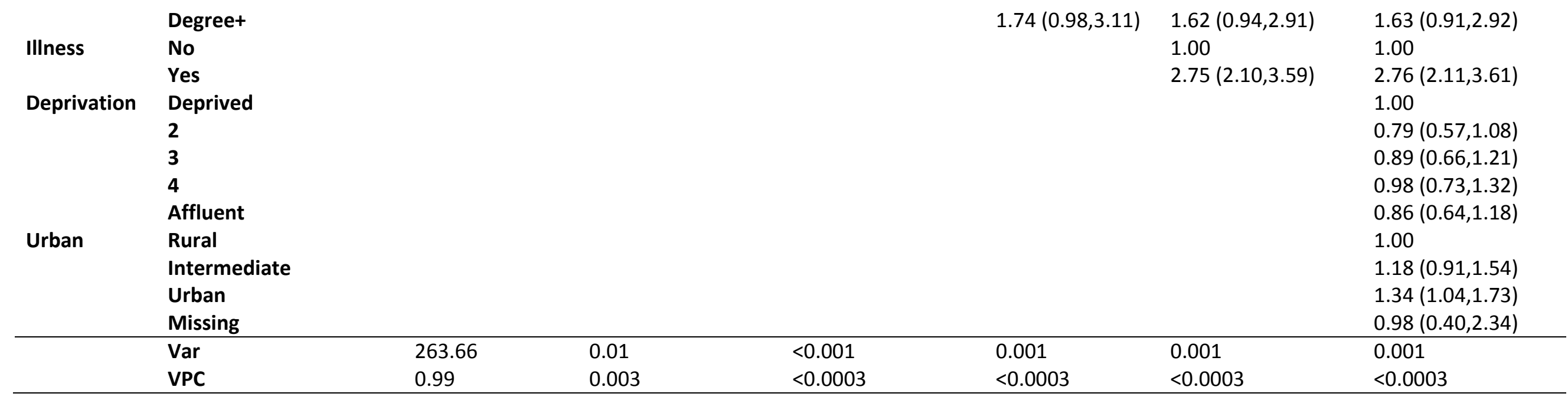




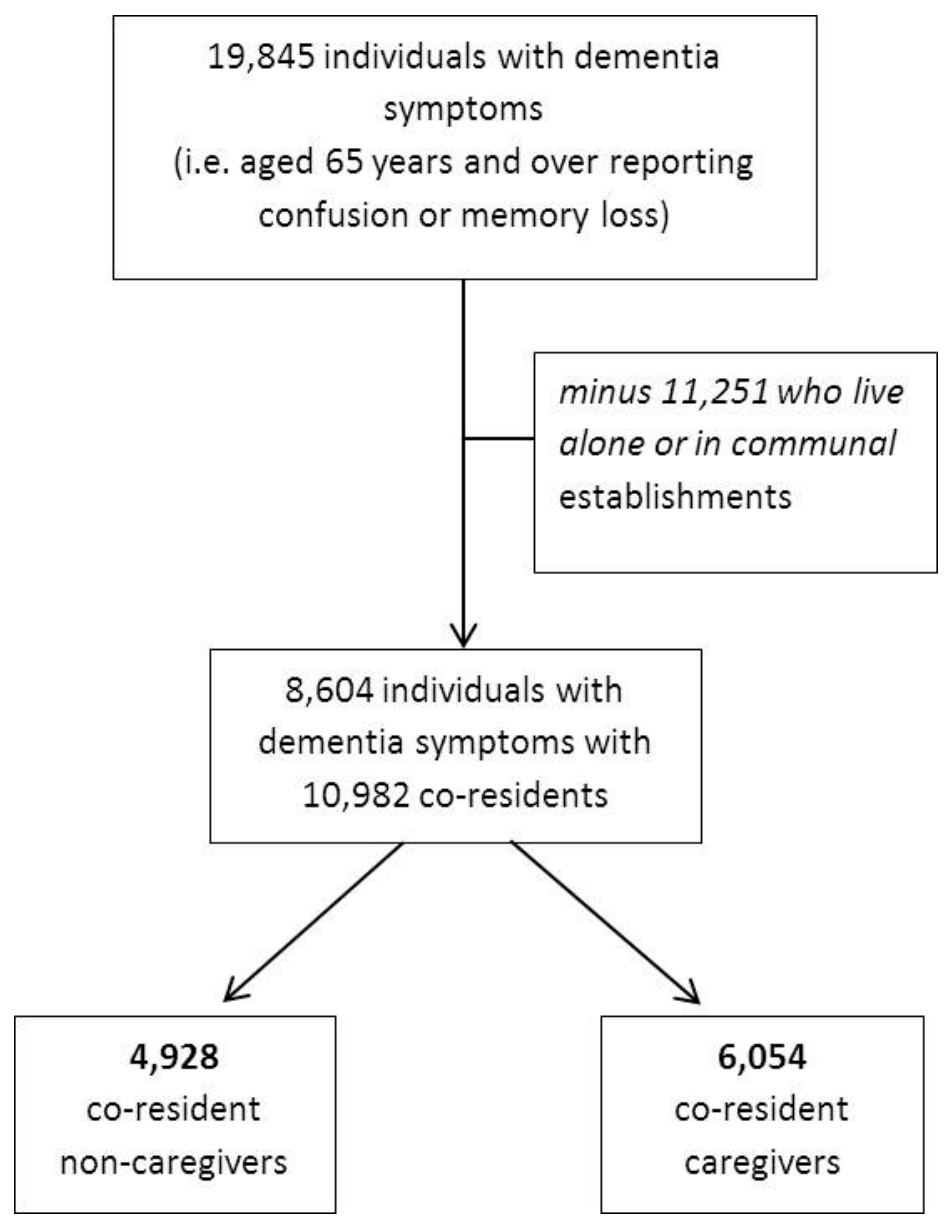

Figure 1: Identification of cases (co-resident caregivers) and controls (co-resident non-caregivers) 


\section{References}

Alzheimer's Society, 2014. Northern Ireland Diagnosis Rate. Alzheimer's Society.

Amirkhanyan, A., Wolf, D., 2003. Caregiver stress and noncaregiver stress: exploring the pathways of psychiatric morbidity. Gerontologist 43, 817-827.

Arai, Y., Kumamoto, K., Mizuno, Y., Washio, M., 2014. Depression among family caregivers of community-dwelling older people who used services under the Long Term Care Insurance program: a large-scale population-based study in Japan. Aging Ment. Health 18, 81-91.

Ask, H., Langballe, E., Holmen, J., Selbæk, G., Saltvedt, I., Tambs, K., 2014. Mental health and wellbeing in spouses of persons with dementia: the Nord-Trøndelag health study. BMC Public Health 14, 413.

Ayalon, L., 2011. The IQCODE versus a single-item informant measure to discriminate between cognitively intact individuals and individuals with dementia or cognitive impairment. J. Geriatr. Psychiatry Neurol. 24, 168-173.

Brown, R.M., Brown, S.L., 2014. Informal Caregiving: A Reappraisal of Effects on Caregivers. Soc. Issues Policy Rev. 8, 74-102.

Brown, S.L., Brown, R.M., 2015. Connecting prosocial behavior to improved physical health: Contributions from the neurobiology of parenting. Neurosci. Biobehav. Rev. 55, 1-17.

Brown, S.L., Smith, D.M., Schulz, R., Kabeto, M.U., Ubel, P.A., Poulin, M., Yi, J., Kim, C., Langa, K.M., 2009. Caregiving Behavior Is Associated With Decreased Mortality Risk. Psychol. Sci. 20, 488-494. 
Capistrant, B.D., Berkman, L.F., Glymour, M.M., 2014. Does duration of spousal caregiving affect risk of depression onset? Evidence from the health and retirement study. Am. J. Geriatr. Psychiatry 22, 766-770.

Cohen, C.A., Colantonio, A., Vernich, L., 2002. Positive aspects of caregiving: Rounding out the caregiver experience. Int. J. Geriatr. Psychiatry 17, 184-188.

Cohen, G., Forbes, J., Garraway, M., 1995. Interpreting self reported limiting long term illness. BMJ 311, 722-4.

Cuijpers, P., 2005. Depressive disorders in caregivers of dementia patients: a systematic review. Aging Ment. Health 9, 325-330.

DHSSPS, 2011. Improving Dementia Services in Northern Ireland (Department of Health Social Services and Public Safety Northern Ireland).

Ferri, C.P., Prince, M., Brayne, C., Brodaty, H., Fratiglioni, L., Ganguli, M., Hall, K., Hasegawa, K., Hendrie, H., Huang, Y., Others, 2006. Global prevalence of dementia: a Delphi consensus study. Lancet 366, 2112-2117.

Fredman, L., Cauley, J. a., Hochberg, M., Ensrud, K.E., Doros, G., 2010. Mortality associated with caregiving, general stress, and caregiving-related stress in elderly women: Results of caregiver-study of osteoporotic fractures. J. Am. Geriatr. Soc. 58, 937-943.

Gruenewald, T.L., Karlamangla, A.S., Greendale, G. a, Singer, B.H., Seeman, T.E., 2007. Feelings of Usefulness to Others, Disability, and Mortality in Older Adults: the MacArthur Study of Successful Aging. J. Gerontol. B. Psychol. Sci. Soc. Sci. 62, P28-P37. Hassink, W.H.J., Van den Berg, B., 2011. Time-bound opportunity costs of informal care: 
Consequences for access to professional care, caregiver support, and labour supply estimates. Soc. Sci. Med. 73, 1508-1516.

Hendry, K., Quinn, T.J., Evans, J.J., Stott, D.J., 2015. Informant single screening questions for delirium and dementia in acute care - a cross-sectional test accuracy pilot study. BMC Geriatr. 15, 17.

Hill, P.L., Turiano, N. a, 2014. Purpose in Life as a Predictor of Mortality Across Adulthood. Psychol. Sci. 25, 1482- 1486.

Hollander, M., Chappell, N., 2007. A Comparative Analysis of Costs to Government for Home Care and Long-term Residential Care Services, Standardized for Client Care Needs. Can. J. Aging 26, 149-161.

Leon, J., Moyer, D., 1999. Potential cost savings in residential care for Alzheimer's disease patients. Gerentologist 39, 440-449.

Loi, S.M., Dow, B., Moore, K., Hill, K., Russell, M., Cyarto, E., Malta, S., Ames, D., Lautenschlager, N.T., 2015. The adverse mental health of carers: Does the patient diagnosis play a role? Maturitas $82,134-138$.

NISRA, 2005. Report of the Inter-Departmental Urban-Rural Definition Group. Statistical classification and delineation of settlements.

NISRA, 2010. Northern Ireland Multiple Deprivation Measure (NIMDM).

O’Reilly, D., Connolly, S., Rosato, M., Patterson, C., 2008a. Is caring associated with an increased risk of mortality? A longitudinal study. Soc. Sci. Med. 67, 1282-90.

O’Reilly, D., Rosato, M., Catney, G., Johnston, F., Brolly, M., 2012. Cohort description: the 
Northern Ireland Longitudinal Study (NILS). Int. J. Epidemiol. 41, 634-41.

O’Reilly, D., Rosato, M., Connolly, S., 2008b. Unlinked vital events in census-based longitudinal studies can bias subsequent analysis. J. Clin. Epidemiol. 61, 380-5.

O’Reilly, D., Rosato, M., Maguire, A., Wright, D., 2015a. Caregiving reduces mortality risk for most caregivers: a census-based record linkage study. Int. J. Epidemiol.

O’Reilly, D., Rosato, M., Maguire, A., Wright, D., 2015b. Caregiving reduces mortality risk for most caregivers: a census-based record linkage study. Int. J. Epidemiol. 1-11.

Papastavrou, E., Charalambous, A., Tsangari, H., Karayiannis, G., 2012. The Burdensome and Depressive Experience of Caring: What Cancer, Schizophrenia, and Alzheimer's Disease Caregivers Have in Common. Cancer Nurs. 35, 187-194.

Pearlin, L.I., Menaghan, E.G., Lieberman, M.A., Mullan, J.T., 2011. The Stress Process. J. Health Soc. Behav. 22, 337-356.

Ramsay, S., Grundy, E., O’Reilly, D., 2013. The relationship between informal caregiving and mortality: an analysis using the ONS Longitudinal Study of England and Wales. J. Epidemiol. Community Health 67, 655-60.

Rodrigues, R., Huber, M., Lamura, G., 2012. Facts and Figures on Healthy Ageing and Longterm Care Europe and North America.

Roth, D., Dilworth-Anderson, P., Huang, J., Gross, A., Gitlin, L., 2015a. Positive Aspects of Family Caregiving for Dementia: Differential Item Functioning by Race. Journals Gerontol. Ser. B Psychol. Sci. Soc. Sci. 70, 813-819.

Roth, D., Fredman, L., Haley, W., 2015b. Informal Caregiving and Its Impact on Health: A 
Reappraisal From Population-Based Studies. Gerontologist 55, 309-319.

Roth, D.L., Haley, W.E., Hovater, M., Perkins, M., Wadley, V.G., Judd, S., 2013. Family caregiving and all-cause mortality: findings from a population-based propensitymatched analysis. Am. J. Epidemiol. 178, 1571-8.

Schulz, R., Beach, S.R., 1999. Caregiving as a risk factor for mortality: the Caregiver Health Effects Study. JAMA 282, 2215-2219.

Schulz, R., O’Brien, A.T., Bookwala, J., Fleissner, K., 1995. Psychiatric and physical morbidity effects of dementia caregiving: prevalence, correlates, and causes. Gerontologist 35, 771-791.

Smith, L., Onwumere, J., Craig, T., McManus, S., Bebbington, P., Kuipers, E., 2014. Mental and physical illness in caregivers: results from an English national survey sample. Br. J. Psychiatry 197-203.

Tseliou, F., Maguire, A., Donnelly, M., O’Reilly, D., 2015. The impact of childhood residential mobility on mental health outcomes in adolescence and early adulthood : a record linkage study. J. Epidemiol. Community Heal. 0, 1-8.

Van Den Berg, B., Fiebig, D.G., Hall, J., 2014. Well-being losses due to care-giving. J. Health Econ. 35, 123-131.

Vitaliano, P.P., Strachan, E., Dansie, E., Goldberg, J., Buchwald, D., 2014. Does Caregiving Cause Psychological Distress? The Case for Familial and Genetic Vulnerabilities in Female Twins. Ann. Behav. Med. 47, 198-207. 